\title{
OPTIMUM GEOMETRY AND INITIAL SHAPE FINDING OF CABLE STAYED BRIDGES
}

\author{
Zidan, M., Fayed, M.N., Shuaib, M.F., and Hilal, M.A.
}

\begin{abstract}
The optimum geometry design of cable stayed bridges could help in the material and the cost minimization of such structures. An optimum design algorithm has been proposed for the analysis and design of Cable Stayed Bridges (CSB), for their minimum weight. In this procedure, a computational method is presented to determine the initial shape of cable stayed bridges under the action of dead load of the girders and pretension in stay cables. The proposed optimum geometry design is achieved to satisfy both stress and displacement constraints, considering the member sizes and the geometrical design variables. A hybrid method is proposed by using the combination of a derived optimality criterion method and the suggested fully utilized design algorithm. Numerical investigations are performed to verify both the efficiency and the mathematical robustness of the proposed algorithm. The practical applicability of the proposed algorithm is made on the Suez Canal cable stayed bridge; the obtained results are analyzed and discussed.

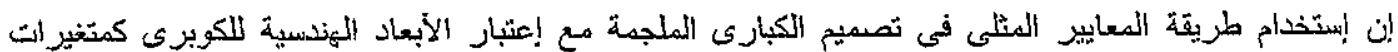

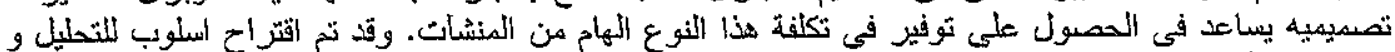

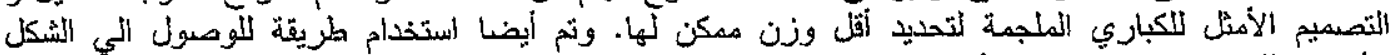

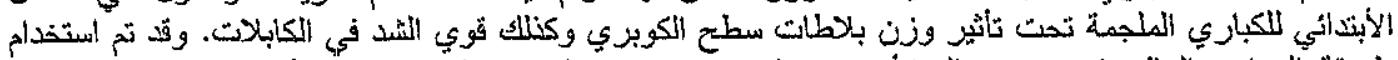

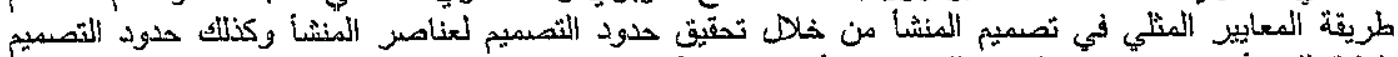

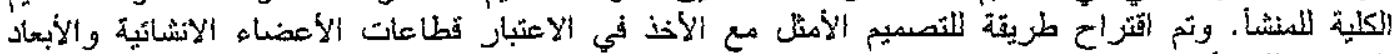

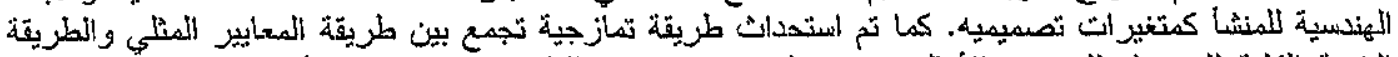

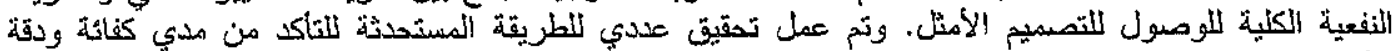

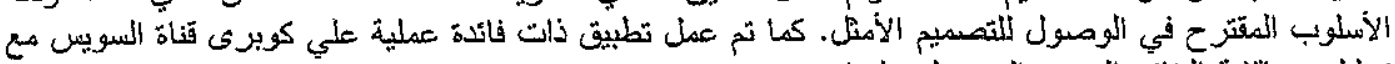

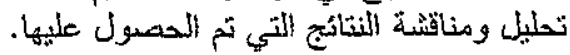

Keywords: Optimum Geometry Design, Initial Shape, Cable Stayed Bridges.

\section{INTRODUCTION}

Cable-stayed bridges are very appealing aesthetically and are very important lifeline structures [1,2 and 3]. The optimurn design of cable stayed bridges is usually a nonlinear mathematical problem, the nonlinearity exits in both the design and the structural behavior. This may lead to oscillation and divergence in the pass to reach the optimum design. The initial shape finding of cable stayed bridges is carried out to reduce the deflection and to smooth the bending moments in the main girder. The initial shape of a cable-stayed bridge provides the geometric configuration as well as the pre-stress distribution of the bridge under the action of girder dead load and the pretension forces in the inclined stays $[4,5$ and 6$]$.

In the present work, an optimum design algorithm for cable stayed bridges, is proposed based on the optimality criteria conditions and the gradient methods. The optimum resizing of structural members is carried out using the optimality criteria methods with displacement, stress, and buckling constraints. A detailed hybrid method is proposed for the optimum geometry design of cable stayed bridges. The proposed algorithm combines a developed optimality criterion and the suggested modified fully utilized design method for the shape optimization of structures. The proposed optimum geometry algorithm is applied on some of the published design problems and an existing cablestayed bridge to explore the efficiency, reliability, and applicability of that algorithm [7]. Discussion of the results is presented to show the effectiveness and capability of the proposed algorithm.

\section{STATIC ANALYSIS BY ENERGY METHOD}

The total potential energy in displacement space

Total potential energy (W) of the structure can be written as [8 and 9]:

$W=\sum_{n=1}^{f}\left[U_{o f}+\sum_{s=1}^{12} \sum_{r=1}^{12} 1 / 2 x_{s} K_{s r} x_{r}+\sum_{s=1}^{12}\left(Q_{x}\right) x_{s}\right]_{n}+$ 
$\underset{n=1}{p}\left[U_{o p}+T_{a} e+\left(E A / 2 L_{o}\right) e^{2}\right]_{n}-\underset{n=1}{N} F_{n} x_{n}$

Where,

Where; $\left(\mathrm{U}_{\mathrm{o}} \mathrm{N}\right)$ is the initial potential energy; $(\mathrm{N})$ and (f) are the total number of members and degrees of freedom respectively; $\left(x_{s}, x_{r}\right.$, and $\left.x_{n}\right)$ are the displacement vectors; $\left[\mathrm{K}_{\mathrm{sr}}\right]$ is the tangent stiffness matrix; $\left(Q_{x}\right)$ is the finite deflection force and $\left(F_{n}\right)$ is an element of the applied loads. ( $T_{0}$ ) is the initial tension force in cable members. (e) is the elongation of cable member or pre-stressed pin jointed-member, from $(x)$ to $(x+D x)$ in displacement space.

\section{Minimization of the total potential work}

The displacement vector $[x]$ is found from the following iterative process $[12,13$ and 1$]$ :

$$
[\mathrm{x}]_{\mathrm{k}+1}=[\mathrm{x}]_{\mathrm{k}}+\mathrm{S}_{\mathrm{k}}(\mathrm{v})_{\mathrm{k}}
$$

in which , $k=$ iterative index, $S_{k}=$ step length, $[v]_{k}$ $=$ conjugate gradient vector for iteration $\mathrm{k}$.

For each iteration cycle, the current values of the conjugate gradient vector $[\mathrm{v}] \mathrm{k}$, are determined from:

$$
[\mathrm{v}]_{\mathrm{k}}=-[\mathrm{g}]_{\mathrm{k}}+\mathrm{B}_{\mathrm{k}}[\mathrm{v}]_{\mathrm{k}-\mathrm{l}}
$$

where, $[g]$ is the gradient vector and $B_{k}$ is determined from Fletcher-Reeves [12 and 13] formula for conjugate gradients, given by :

$$
\mathrm{B}_{\mathrm{k}}=[\mathrm{g}]_{\mathrm{k}}^{\mathrm{T}}[\mathrm{g}]_{\mathrm{k}} /[\mathrm{g}]_{\mathrm{g}-1}{ }^{\mathrm{T}}[\mathrm{g}]_{\mathrm{k}-1}
$$

\section{Initial Shape Finding Of Cable-Stayed Bridges}

The computation of initial shape finding starts with zero or very small tensile forces in the inclined cables [4 and 5], based on reference configuration having no deflection in girders and zero pre-stress in any element. The equilibrium position of the cablestayed bridge under dead load action is first determined iteratively by the energy method. This first determined configuration satisfies the equilibrium conditions and also the boundary condition. For shape iteration, the cable axial determined in the previous step will be taken as initial element forces for inclined cables. A new equilibrium configuration and such cable initial forces will be determined again. During shape iterations, several control points (nodes of intersection between girder and cables) will be chosen for checking if the convergence tolerance is achieved or not. In each shape iteration, the ratio of vertical displacements at the control points to the main span length will be checked.

$$
\left|\frac{\text { Vertical displacement at each control point }}{\text { main span length }}\right| \leq \varepsilon_{\text {s }}
$$

The shape iteration will be repeated until the convergence tolerance $\varepsilon_{s}$ is achieved.

\section{OPTIMUM DESIGN APPROACH}

\section{I - Members Resizing Algorithm}

\section{Problem Formulation}

The optimum structural design problem can be defined as finding the design variable vector that minimizes the objective function (the total volume of the structure) in the following form [8,13 and 14]:

$\Psi=\sum_{\mathrm{i}=1}^{\mathrm{NE}} \mathrm{A}_{\mathrm{i}} \mathrm{L}_{\mathrm{i}}$

Satisfying

$g_{\mathrm{k}}=\sum_{\mathrm{n}=1}^{\mathrm{fi}}\left[\sum_{n=1}^{12}\left(\mathrm{~K}_{\mathrm{sr}} \mathrm{x}_{\mathrm{r}}\right)\right]_{n}+\sum_{\mathrm{n}=1}^{\mathrm{pi}}\left[\mathrm{s}_{o}+\frac{\mathrm{EA}}{L} \cdot e\right]_{n} \frac{\partial e}{\partial x}-F_{\mathrm{s}}=0$

$\mathrm{s}=1 \ldots . ., \mathrm{nn}$

Subjected to stress constraints

$$
\begin{array}{lr}
\mathrm{G}_{\mathrm{s}}=\mathrm{f}_{\mathrm{ik}}-\mathrm{F}_{\mathrm{ik}} \leq 0 & \mathrm{i}=1, \ldots \ldots, \mathrm{P}_{1} \\
\mathrm{k}=1, \ldots \ldots, \mathrm{nLc} & \\
\mathrm{A}_{\mathrm{i}} \geq \mathrm{A}_{\min } & \mathrm{i}=1, \ldots \ldots, \mathrm{ng}
\end{array}
$$

and displacement constraints

$$
\begin{aligned}
\mathrm{G}_{\mathrm{d}}=\mathrm{U}_{\mathrm{jk}}-\overline{\mathrm{U}}_{\mathrm{jk}} \leq 0 \quad & \\
& \mathbf{i}=1, \ldots, \ldots, \mathrm{P}_{2} \\
\mathbf{k} & =1, \ldots \ldots, \mathrm{nLC}
\end{aligned}
$$

Where, $\psi=$ objective function, $L_{i}=$ length of member $i, A_{i}=$ the cross sectional area of $i^{\text {th }}$ member, $\mathrm{NE}=$ total number of elements, $\mathrm{g}_{\mathrm{s}}(\mathrm{A}, \mathrm{x})$ $=\mathrm{s}^{\text {th }}$ element in the gradient vector of the total potential energy, $G_{s}=$ stress constraints, $G_{d}=$ displacement constraints, $U_{j k}=$ the actual nodal displacement in the $\mathrm{j}^{\text {th }}$ constrained degree of freedom , $\widetilde{\mathrm{U}}_{\overparen{ }}=$ the allowable nodal displacement in the $\mathrm{j}^{\text {th }}$ constrained degree of freedom, $\mathrm{f}_{\mathrm{ik}}=$ the actual stress in $\mathrm{i}^{\text {th }}$ member due to the $\mathrm{k}^{\text {th }}$ case of loading condition ,$F_{i k}=$ the allowable stress in the $i^{\text {th }}$ member, $n n=$ total number of degrees of freedom, $P_{1}=$ the number of stress constraint, $P_{2}=$ the number of displacement constraints, $\mathrm{ng}=$ number of member groups, $\mathrm{x}=$ displacement variable vector.

A number of ways to establish the relationships between the design variables and the desired sectional properties have been suggested to remove the aforementioned difficulties [13]. 
Zidan, M., Fayed, M.N., Shuaib, M.F, and Hilal, M.A., "Optimum Geometry and Initial Shape Finding ... "

\section{Stress Constraints Dominance}

The following stress ratio recursion formula, which is frequently used for stress constrained problem can be used [13];

$\left(\mathrm{A}_{\mathrm{i}}\right)_{v+1}=\left[\left(\frac{\max \left|f_{i k}\right|^{\gamma}}{c_{1} F_{i}}\right)\right]\left(\mathrm{A}_{\mathrm{i}}\right)_{v}$

where, $c_{1}=\mathrm{a}$ constant which ranges from 0.990 to 1.00 and $\gamma=$ a constant which ranges from 0.3 to 1.0 .

\section{Displacement Constraints Dominance}

The recursion equation was developed as follows [15 and 16].

$\left(\mathrm{A}_{i}\right)_{v+1}=\left[\left(\frac{U_{P q}}{C_{2} \overline{\bar{U}}_{P}}\right)^{\alpha}\left\{\lambda_{P q} \frac{G_{i}}{L_{i}}\right\}^{\xi} A_{i}\right]_{\nu}$

where $\square=$ exponent equals $0.75, \square=$ relaxation parameter that ranges between 0.003 and 0.6 and $C_{2}$ $=\mathrm{a}$ constant that ranges between 0.985 and 0.999 when $U_{p q}>\hat{U}_{p}$ otherwise its value is 1.0 .

\section{II- Optimum Geometry Design Algorithm}

a-A Derived Optimality Criterion

Applying the Kuhn-Tucker conditions for optimality conditions considering the geometry design variables $\left(\mathrm{L}_{\mathrm{xr}}\right)$, then [17]:

$$
\begin{aligned}
& \left(\mathrm{L}_{\mathrm{xr}}\right)_{\mathrm{n}+1}=\left(\mathrm{L}_{\mathrm{xx}}\right)_{\mathrm{n}}\left\{\left(\mathrm{u}_{\mathrm{p}} / \mathrm{C}_{1} \mathrm{u}_{\mathrm{p}}\right)^{\alpha}\right)^{*} \\
& \left.\left\{\left(1 / \sum_{\mathrm{i}=1}^{N} \mathrm{a} A_{i}[\operatorname{Cos}(\alpha)]_{\mathrm{i}}\right)\left[\sum_{\mathrm{j}=1}^{\mathrm{J}} \lambda_{\mathrm{p}}\left(\partial \mathrm{u} / \partial \mathrm{L}_{\mathrm{xx}}\right)\right]\right\}^{\eta^{\mathrm{n}}}\right\}_{\mathrm{n}}
\end{aligned}
$$

Where: (a) is an exponent which ranges between 0.65 and $1.00 ;(\eta)$ is a relaxation parameter that ranges between 0.003 and $0.600 ;\left(C_{1}\right)$ is a constant which ranges between 0.985 and 0.999 when $\left(\mathrm{u}_{\mathrm{j}}>\mathrm{u}_{\mathrm{j}}{ }^{*}\right)$ otherwise it equals to 1.000 ; and $(n)$, and $(n+1)$ indicate the indexes of the current iteration and the next iteration respectively.

\section{b- The Suggested Fully Utilized Design}

In this work, the geometry $\left(\alpha_{x x}\right)$ [10], design variables; and to apply the optimality criteria to the active design variables.

$$
\left(L_{x r}\right)_{n+1}=\left(L_{x r}\right)_{n}\left\{(r+1)-r^{*} \operatorname{Maximum}\left(g_{1} / g_{1}\right)^{\circ}\right\}
$$

Where, $\left(X_{i}\right)_{n}$ is the current passive design variables; both $g_{j}$ and $g_{j}^{*}$ are the actual and limiting constraints' yalues respectively; and $(r)$ is the relaxation parameter which tends to zero near optimum design.

\section{c- The Proposed Optimum Geometry Algorithm}

A proposed design algorithm is generated by combining both the developed optimally criteria method and the suggested [FUD] method. In this method, the optimality criteria method is applied for the first iterations, then the optimum geometry design is using the Fully Utilized Design method to reach the optimum design. The generated optimum design procedure is both efficient and reliable. The proposed method for optimum geometry design of cable stayed bridges can be summarized as shown in Figure (1) .

\section{COMPARATIVE DESIGN PROBLEMS}

\section{Three bars truss}

The proposed optimum geometry design algorithm is applied to the optimum design of the famous three-bars truss shown in figure (2). This design problem was previously solved by Bremicker et al. [18]. The design variables are the crosssectional areas of truss members that are divided into three groups and the horizontal distance (b). Thus, this is an optimum geometry design problem. The structure is subjected to stress constraints under the action of two loading conditions acting at joint $I$ as shown in the figure where:

$$
\begin{array}{lll}
\text { Case (I): } & P_{3}=-100 \mathrm{kN} & P 2=-100 \mathrm{kN} \\
\text { Case (II): } & P_{1}=100 \mathrm{kN} & \mathrm{P} 2=-100 \mathrm{kN}
\end{array}
$$

Truss design parameters are as follows: the material modulus of elasticity $(E)=2100 \mathrm{kN} / \mathrm{mm}^{2}$, the material density $(\rho)=7.85 \times 10^{-6} \mathrm{~kg} / \mathrm{mm}^{3}$, the allowable stress is $0.20 \mathrm{kN} / \mathrm{mm}^{2}$ for both tensile and compressive stresses, the minimum cross-sectional area is $1 \mathrm{~mm}$, the lower bound on the geometry design variable distance (b) is $400 \mathrm{~mm}$, and its upper bound is $2000 \mathrm{~mm}$.

The proposed hybrid method is performed on this problem. The obtained minimum weight is $14.179 \mathrm{~kg}$ after 7 iterations. The minimum weight, which was informed by Bermicker et al. [2], is $14.173 \mathrm{~kg}$ after 29 iterations, i.e. the obtained optimum weight is relatively the same as the published optimum weight, and it is accompanied by an efficient reduction of number of iterations. The obtained optimum distance (b) is $661.27 \mathrm{~mm}$ which is bigger than $657.99 \mathrm{~mm}$ of Bremicker [2].The comparison of results is presented in Table (l) including the obtained results by this work and those of literature. 


\section{Initial Shape Finding of Symmetrical Harp Cable-Stayed Bridges}

A symmetrical harp cable-stayed bridge is taken from Ref. [5]. Its Geometrical properties are shown in Fig.(3). The shape iteration control points are taken at joints 5,6 , and 7 . The vertical displacements at these joints are checked during shape iterations. Four shape iterations are performed until reaching an accuracy $\varepsilon_{\mathrm{s}}=10^{-4}$. The moments, shear, and axial force diagrams of the girder are plotted in Fig. (4). The cable forces, vertical deflection at the control points, and maximum positive and negative bending moments in the girder of the symmetrical harp cablestayed bridge, are listed in Tables (2,3 and 4). From the listed results, it is clear that in this example, the deflection, maximum moments, and shear forces in the girder, are considerably reduced and the diagrams become very smooth after the shape iterations. The axial force in girder slightly increases after shape iteration because of increasing in pretension forces in the cables.

\section{Optimum Geometry Design of Suez-Canal Cable-Stayed Bridge}

A real bridge (Suez-Canal cable-stayed bridge) is chosen as a case study [19 ]. Suez Canal double plane cable-stayed bridge, Fig. (5) is a high way road bridge with central span of $404 \mathrm{~m}$ and two side spans of $163 \mathrm{~m}$. Its two towers have total height of $155 \mathrm{~m}$ each one, which is made of reinforced concrete box sections in the form of $\mathrm{H}$-shaped frame. 128 Cables are arranged in a double plane over the bridge length, with $10-12 \mathrm{~m}$ spacing, in a semi fan pattern. The original design of the deck consists of a steel box girder having a wide of $20.8 \mathrm{~m}$ (4 traffic lanes, $0.8 \mathrm{~m}$ side walks and $1.2 \mathrm{~m}$ median strip) and a depth varied from $1.2 \mathrm{~m}$ at the edges to $2.6 \mathrm{~m}$ at the middle. The upper and lower decks are made from orthotropic plates with closed ribs. The outer sides and the two longitudinal stiffeners are made from solid plates of thickness $16 \mathrm{~mm}$ and $11 \mathrm{~mm}$ respectively. At cables locations and at mid-distance between cables, solid steel cross diaphragms are used of a thickness of $10 \mathrm{~mm}$ for the purpose of strengthening the section. The consummation of steel $\mathrm{per} / \mathrm{m}^{2}$ of deck was found approximately $480 \mathrm{~kg} / \mathrm{m}^{2}$.

\section{- Used Materials:}

*The reinforced concrete with 28 days crushing strength $\mathrm{Ccu}=500 \mathrm{~kg} / \mathrm{cm}^{2}$

*Concrete Young's modulus of elasticity $(E)=$ $335 \mathrm{t} / \mathrm{cm}^{2}$

*Reinforcing steel ST 36/52 (Egyptian Standard Specifications)

* Stay Cables $\quad F_{\text {uttimate }}=18000 \mathrm{~kg} / \mathrm{cm}^{2}$

*Young's modulus of elasticity $(\mathrm{E})=2000 \mathrm{t} / \mathrm{cm}^{2}$
- Idealization of the bridge main elements:

Deck: Three different cross sections are chosen for the deck along the longitudinal direction of the bridge as shown on Fig. (5). The cross section areas for the said sections are given in Table (5). These parameters are calculated from the actual configuration of the deck cross sections.

The design relations linking the deck cross sectional area $\left(A_{D}\right)$ with its section modulus $\left(S_{D}\right)$, and moment of inertia $\left(I_{D}\right)$ can be expressed as follows:

$\mathrm{I}_{\mathrm{D}}=\frac{12 A_{D} H^{3}}{(H+W / 2)}+\frac{10 A_{D}^{3}}{3(4 H+2 W)^{3}}+\frac{2.5 A_{D} H^{2}}{(H+W / 2)}$

$\mathrm{S}_{\mathrm{D}}=\frac{A_{D} H^{2}}{6(H+W / 2)}+\frac{20 A_{D}^{3}}{3 H(4 H+2 W)^{3}}+\frac{5 A_{D} H}{(H+W / 2)}$

Where; $(H)$ is the given deck depth; and $(W)$ is the given deck width, as shown on Figure (6).

Cables: The cables shown on Fig. (5) are divided to four groups. The cross section area for each group is taken from the structural drawings of the bridge and is summarized in Table (5).

Pylons: The pylon has variable cross section along its height; four different cross sections are selected to represent the variation of the pylon. The cross sections of one leg of the pylons of the bridge are presented in table (5). The pylon section in the present study is assumed as hollow box section as shown on Figure (6). The design relations linking the Pylon cross-sectional area $\left(A_{P}\right)$ with its section modulus $\left(\mathrm{S}_{P}\right)$, and moment of inertia $\left(\mathrm{I}_{P}\right)$ can be expressed as follows:

$$
\begin{aligned}
& \mathrm{I}_{\mathrm{P}}=\frac{1}{12}\left[2 \mathrm{~A}_{\mathrm{P}}\left(\frac{\mathrm{A}_{\mathrm{P}}+4 \mathrm{t}^{2}}{4 \mathrm{t}}\right)^{2}-\mathrm{A}_{\mathrm{P}}^{2}\right] \\
& \mathrm{S}_{\mathrm{P}}=\frac{2 t}{3\left(A_{P}+4 t^{2}\right)}\left[2 \mathrm{~A}_{\mathrm{P}}\left(\frac{A_{P}+4 t^{2}}{4 t}\right)^{2}-\mathrm{A}_{\mathrm{P}}^{2}\right]
\end{aligned}
$$

Where; $(t)$ is the given wall thickness of the pylon.

The initial shape iterations procedure as well as the proposed hybrid method is performed on the Suez Canal Bridge, assuming the design variables as the cross-sectional areas of the bridge elements and the Pylon Height $\left(\mathrm{H}_{\mathrm{T}}\right)$. The results show that the optimum weight / quantities can be obtained at pylon height of $167 \mathrm{~m}$ instead of $155 \mathrm{~m}$ (assuming the height of pylon below the deck is fixed). The ratio between the optimum areas (weight) obtained in this study and the existing deck areas (weight) is ranged between $75 \%$ and $95 \%$. Also, the same ratio in pylons gives a percentage ranged between $79 \%$ and $102 \%$. However, in cables, such ratio is ranged between $104 \%$ to $200 \%$ (at short cables). 


\section{SUMMARY AND CONCLUSIONS}

In this paper, a proposed procedure that is practically applicable to the optimum design problems of cable stayed bridges has bean introduced taking into consideration initial shape finding of cable stayed bridges. The structural analysis is carried out by minimization of the total potential energy of the structure by conjugate gradient technique. The optimum design is achieved to satisfy the constraints of the design variables using the optimality criteria method. A recurrence relation with relaxation factors for updating the design variables is implemented to obtain faster and more rates of convergence to the optimum design.

The use of this proposed procedure shows how successful it is in solving two examples available in the literature for optimum geometry design and initial shape finding of cable stayed bridges. The structure under: the various constraints such as the stress design variable and displacement constraints can be effectively analyzed and optimized by using the present procedure of solution. Decomposing the imposed constraints into two levels, i.e. the element and structural level constraints and applying them at different stages of optimization made the optimization algorithm in this study very effective. An iterative procedure is performed to represent the efficiency of initial shape finding of cable stayed bridges in reducing the deflection, maximum moments, and shear forces in the girder.

Further, the optimum design of an existing cable stayed bridge was carried out using the procedure. The results show a significant reduction in the deck and pylon quantities (which represent the most effective parameter in the overall bridge quantities) rather than the cables, which increased significantly. However, it can be concluded that the use of optimum geometry design produces a significant reduction in the optimum volume with respect to the optimum volume of the fixed geometry. The presented examples and applications demonstrate the efficiency and robustness of the proposed optimum geometry design. Algorithm which could be applied to the cable stayed bridges with different geometry, the pylon height, or the angles of inclination of the cables, and the member's sizes as the main design variables [19].

\section{REFERENCES}

[1] Krishna, P., " Effect of cable stiffness on cablestayed bridges," Journal of structural engineering, ASCE, Vol. III, No. 9, pp. 20082020, Sept. 1985.

[2] Nazmy, A.S., and Abdel - Gaffar, A.M., " Threedimensional nonlinear static analysis of cable- stayed bridges," Computers and structures, Vol. 34, No. 2, pp. 257-271, 1990.

[3] Ulstrup, C.C., et al., "Guidelines for the design of cable-stayed bridges," ASCE committee on cable-stayed bridges, 1992.

[4] Wang, P. S. N.,Tang, T. Y. and Zheng, H. N., "Analysis of Cable Stayed Bridges during Construction by Cantilever Method Computers and structures, Vol. 82, pp. 329-346, 2004.

[5] Wang, P. H., Tseng, T.C, and Yang, C. G, "Initial shape of cable-stayed bridges". Computers \& Structures, Vol. 47, No. 1, pp. 111-123, 1993.

[6] Ito, M., et al., "Cable-stayed bridges," proceedings of the seminar, Yokohama, Japan, Dec. 1991.

[7] Zidan, M., Fayed, M. N., Shuaib, M., and Hilal, M." Optimization of Long Span Bridges", Under Publication.

[8] Fayed, M. N., "Geometric and Material Nonlinear Analysis of Clad Cable Roof Structures," Scientific Bulletin, Ain Shams University, Vol. 32, No. 3, pp. 93-117, 1997.

[9] Jeusette,J. and Sonzogi, V., " A Projected Conjugated Gradient Method for Structural Stability Analysis with Linear Constraints," Computers \& Structures, Vol. 33, No. 1, pp., 31$39,1993$.

[10] Fletcher, P., and Reeves, C. M., "Function. Minimization by Conjugate Gradients," Computer Joural, Vol. 7, pp. 149-154, 1964.

[11] Karmanov, V. G, "Mathematical Programming," Mir Publ., Moscow, 1989.

[12] Kirsch, U., "Optimum Structural Design," McGraw-Hill, New York, 1981.

[13] Ko, F. and Wang, B., "An Improved Method of Optimality Criteria for Structural Optimal Structural Design Optimization" Computer and struciures, Vol. 41, pp. 629-636, 1991.

[14] Save, M., Prager, M., and Warner, W. H., "Structural Optimization, Volume (1) Optimality Criteria," Plenum Press, New York, 1985.

[15] Khan, M. R., "Optimality Criteria Techniques Applied to Frames Having General CrossSectional Relationships," AIAA J., Vol. 22, No. 5, pp. 669-676, 1984.

[16]Levy, R., and Parzynski, W., " Optimality Criteria Solution Strategies in MultipleConstraint Design Optimization," AIAA J., Vol. 20, No. 5, pp. 708-715, 1981.

[17] Saka, M. P., "Optimum Geometry Design of Roof Trusses by Optimality Criteria Method," Computer and structures, Vol. 38 , No. 1, pp. 83$92,1991$. 
Zidan, M., Fayed, M.N., Shuaib, M.F., and Hilal, M.A., "Optimum Geometry and Initial Shape Finding ... "

[18] Bremicker, M., Papalambrost, P. V., and Loh, H. T., "Solution of Mixed-Discrete Structural Optimization, Problems with a New Sequential Linearization Algorithm," Computers and Structures, Vol. 37, No. 4, pp. 451-461, 1990.
[19] Attabi, M.M., Shaaban, H.M., and Afifi, H.A., "Decking of Cable-Stayed Bridges" Master of Science Thesis, Ain Shams University, Faculty of Engineering, Structural Engineering Department-2001.

Table (1): Comparative results of 3-bar truss.

\begin{tabular}{|c|c|c|}
\hline Design variable & Present work & Bremicker [18] \\
\hline Al (mm2) & 754.084 & 753.74 \\
\hline A2 (mm2) & 1.00 & 1.00 \\
\hline A3 (mm2) & 754.084 & 753.74 \\
\hline b (mm) & 661.27 & 657.99 \\
\hline Weight - (Kg) & 14.18 & 14.173 \\
\hline
\end{tabular}

Table (2): Cable Forces for the Symmetrical Harp Cable-Stayed Bridge.

\begin{tabular}{|c|c|c|c|c|c|c|}
\hline $\begin{array}{c}\text { Shape } \\
\text { Iteration }\end{array}$ & Cable NO. & Force $(\mathrm{kN})$ & Cable NO. & Force $(\mathrm{kN})$ & Cable NO. & Force $(\mathrm{kN})$ \\
\hline 1 & $1-16$ & 13015 & $2-17$ & 6749 & $3-18$ & 5983 \\
\hline 2 & $1-16$ & 13022 & $2-17$ & 8150 & $3-18$ & 7936 \\
\hline 3 & $1-16$ & 12559 & $2-17$ & 8737 & $3-18$ & 8862 \\
\hline 4 & $1-16$ & 12265 & $2-17$ & 9053 & $3-18$ & 9387 \\
\hline
\end{tabular}

Table (3): Deflection for the Symmetrical Harp Cable-Stayed Bridge

\begin{tabular}{|c|c|c|c|c|c|c|}
\hline \multirow{2}{*}{$\begin{array}{c}\text { Shape } \\
\text { Iteration }\end{array}$} & \multicolumn{7}{|c|}{ Vertical deflection (m) } \\
\cline { 2 - 7 } & Joint & Deflection & Joint & Deflection & Joint & Deflection \\
\hline 1 & 5 & -0.5160 & 6 & -1.0550 & 7 & -1.3099 \\
\hline 2 & 5 & -0.2423 & 6 & -0.0819 & 7 & -0.0275 \\
\hline 3 & 5 & -0.0148 & 6 & -0.0072 & 7 & +0.0356 \\
\hline 4 & 5 & -0.0045 & 6 & +0.0017 & 7 & +0.0246 \\
\hline
\end{tabular}


Zidan, M., Fayed, M.N., Shuaib, M.F., and Hilal, M.A., "Optimum Geometry and Initial Shape Finding ... "

Table (4): Maximum Bending Moments for the Symmetrical Harp Cable-Stayed Bridge.

\begin{tabular}{|c|c|c|c|c|}
\hline \multirow{2}{*}{ NSI } & \multicolumn{3}{|c|}{ Maximum bending moments in the gitder $(\mathrm{kN} \mathrm{m})$} \\
\cline { 2 - 5 } & Joint & +ve Moment & Joint & -ve Moment \\
\hline 1 & 8 & 39,189 & 4 & $-106,788$ \\
\hline 2 & 2 & 12,000 & 4 & $-46,037$ \\
\hline 3 & 8 & 11,391 & 4 & $-30,443$ \\
\hline 4 & 8 & 14,100 & 7 & $-26,578$ \\
\hline
\end{tabular}

Table (5): Comparative Results for Suez Canal Cable Stayed Bridge.

\begin{tabular}{|c|c|c|c|c|}
\hline Element & Section & $\begin{array}{c}\text { Actual cross } \\
\text { Sectional- area }\left(\mathbf{m}^{2}\right)\end{array}$ & $\begin{array}{c}\text { Optimized Area in } \\
\text { the present work } \\
\left(\mathbf{m}^{2}\right)\end{array}$ & Ratio \\
\hline Dieck & Segment 1 & 0.8054 & 0.602 & $74.75 \%$ \\
\hline & Segment 2 & 0.8254 & 0.770 & $93.29 \%$ \\
\hline Cables & Segment 3 & 0.8154 & 0.770 & $94.43 \%$ \\
\hline & C1 to C9 \& C24 to C32 & $2 * 0.006706$ & $2 * 0.0070$ & $104.38 \%$ \\
\hline & C10, C11, C22, C23 & $2 * 0.005479$ & $2 * 0.0070$ & $127.76 \%$ \\
\hline Pylon C14 \& C19 to C21 & $2 * 0.004251$ & $2 * 0.0055$ & $129.38 \%$ \\
\hline & C15 to C18 & $2 * 0.002751$ & $2 * 0.0055$ & $199.93 \%$ \\
\hline & Section under Deck & $2 * 16.329$ & $2 * 12.885$ & $78.91 \%$ \\
\hline & Section over Deck Beam & $2 * 9.700$ & $2 * 9.690$ & $99.90 \%$ \\
\hline & Section over upper Beam & $2 * 10.00$ & $2 * 8.160$ & $81.60 \%$ \\
\hline
\end{tabular}




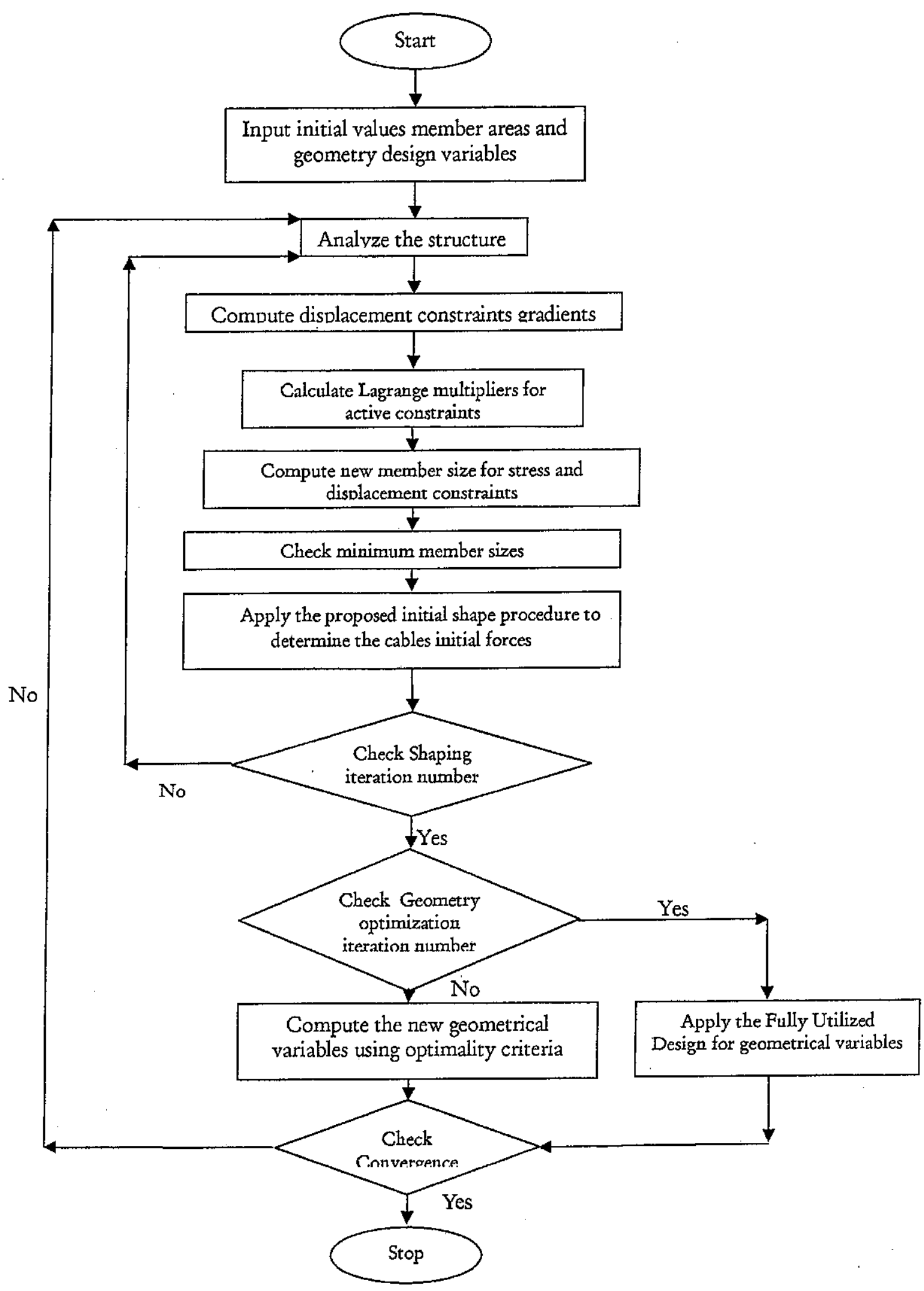

Figure (1) Flow-chart for the Proposed Optimum Geometry Design Algorithm. 
Zidan, M., Fayed, M.N., Shuaib, M.F., and Hilal, M.A., "Optimum Geometry and Initial Shape Finding ... "

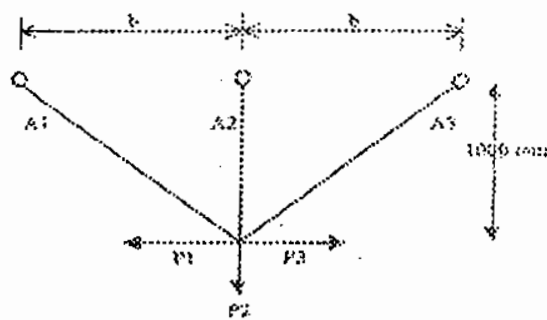

Figure (2) Three-Bars Truss, Initial Shape [18].

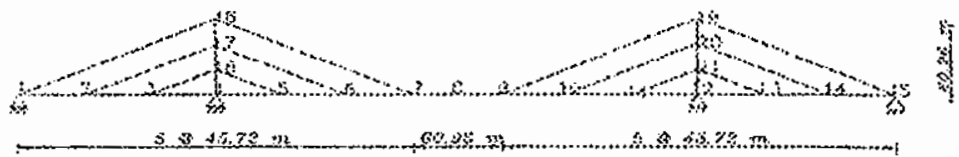

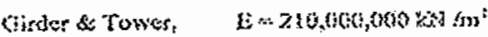

$$
\begin{aligned}
& \text { Cobles. } \quad E=220,090,00 \mathrm{kN} / \mathrm{m}^{2} \\
& \text { Gitries, } \quad \mathrm{i}=1.130 \mathrm{~m}^{2} \mathrm{~A}=0.319 \mathrm{ki}^{2}
\end{aligned}
$$

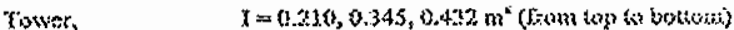

$$
\begin{aligned}
& \text { \& } A=0.203,0.23,5.270 \mathrm{~m}^{2} \\
& \text { Cabie, extering } \wedge \times 0.6430 \mathrm{~m}^{2} \\
& \text { inserios } A-4,016 \% \mathrm{~m}^{2}
\end{aligned}
$$

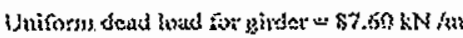

Figure (3) Symmetrical Harp Cable-Stayed Bridge [5].

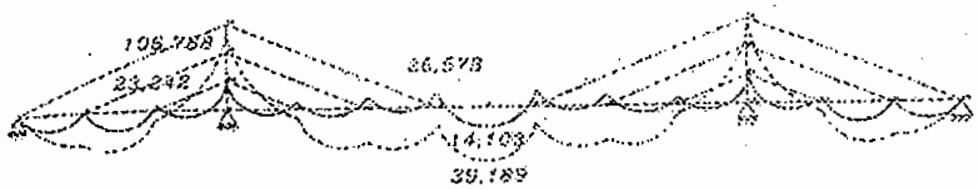

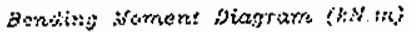
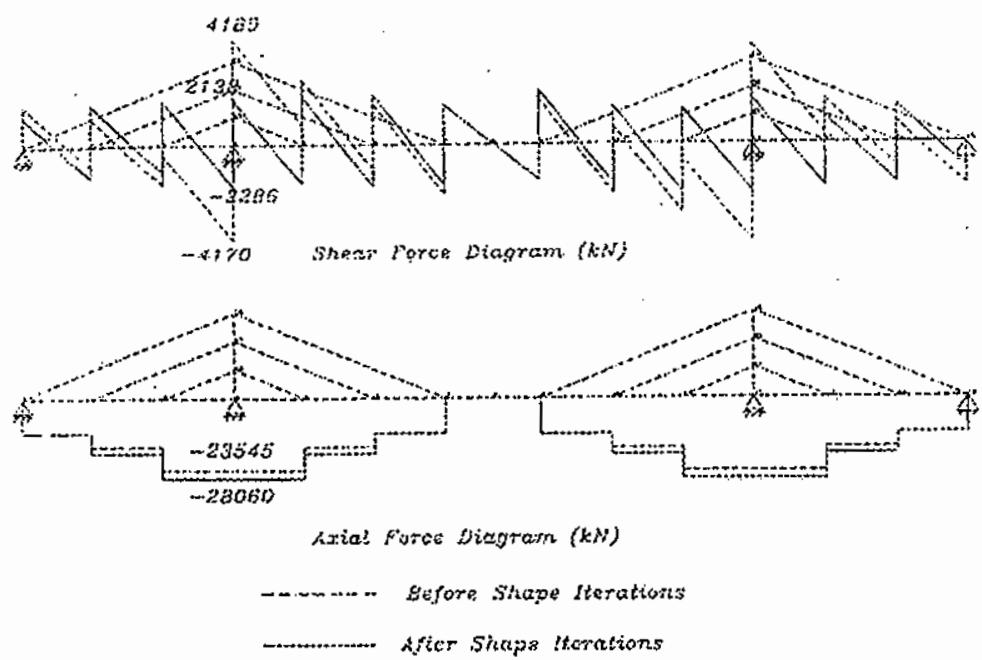

Figure (4) Bending moment, Shear Force, and Axial Force diagrams for Symmetrical Harp Cable-Stayed Bridge 
Zidan, M., Fayed, M.N., Shuaib, M.F, and Hilal, M.A., "Optimum Geometry and Initial Shape Finding ... "

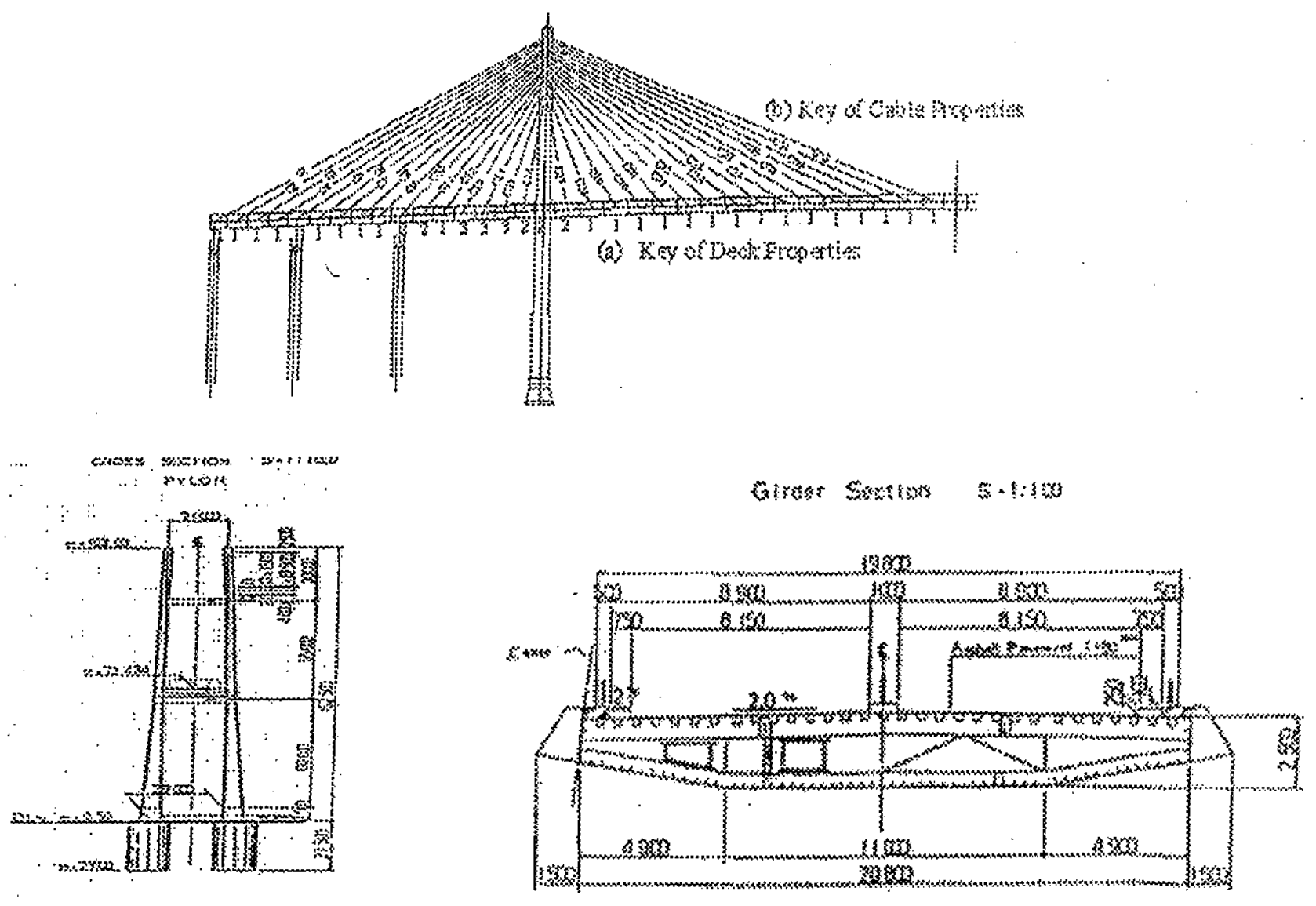

Figure (5) Layout of half Suez-Canal Cable-Stayed bridge [19].
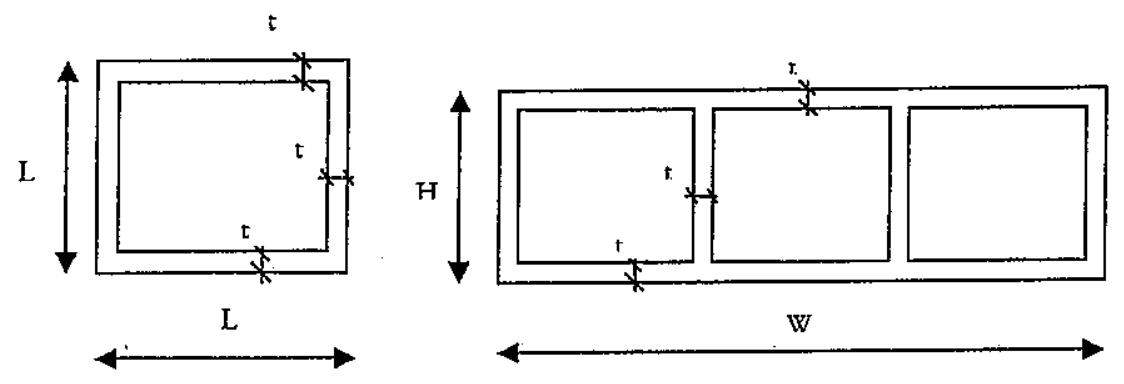

Figure (6) Idealized Cross-sections of the Pylon and Deck of Suez-Canal Cable-Stayed Bridge. 